\title{
Finding our way: Cultural competence and Pākehā evaluators
}

\section{Rae Torrie, Mark Dalgety, Robin Peace, Mathea Roorda, and Robyn Bailey}

Practitioner competence is a critical ingredient in the development of a robust, valid and equitable evaluation. In Aotearoa New Zealand the evaluator competencies identify cultural competence as a core capability. There are some particular challenges that Pākehā (New Zealand European) evaluators face in developing this competency. In grappling with these complex challenges, and in the absence of a pragmatic and systematic way of responding, the writers discuss the use of a heuristic they have developed that may aid enquiry and support evaluators to work in a culturally responsive manner. Three case examples are presented for applying the heuristic in practice. The benefits of, and insights from, using the heuristic are discussed.

\section{Introduction}

Practitioner competence is widely cited in evaluation literature as fundamental to the production of robust, valid and fair evaluations (Bailey, 2010; Jakob-Hoff \& Coggan, 2003; Patton 2015; Stevahn, King, Ghere \& Minnema, 2005) and cultural competence increasingly recognised as an integral component (American Evaluation 
Association, 2011; Hopson, 2009; Kirkhart 1995, 2013; SenGupta, Hopson \& Thompson-Robinson, 2004). In the Aotearoa New Zealand Evaluation Association (ANZEA) competencies, cultural competence is identified as a core capability (ANZEA, 2011).

This article discusses the use of a heuristic, or tool in the form of a diagram, through which evaluators who are Pākehā (New Zealanders of European descent ${ }^{1}$ might pursue the development of cultural competence. We argue that Pākehā evaluators face particular challenges in developing cultural competence, and that this is an issue of importance given that perhaps three-quarters of our self-identified evaluator community (that is, those who are members of ANZEA) are Pākehā. In the article, we name several of the particular challenges Pākehā face and possible reasons for these. We describe a heuristic for categorising different behaviours, actions, attitudes, competencies, and sensibilities that may build toward cultural competence, and propose some ideas for engaging with them. We provide three case examples to demonstrate use of the heuristic and address some of the identified challenges.

We, the authors, are Pākehā evaluators seeking to engage meaningfully with what it means to be culturally competent in our evaluation practice. The challenges we identify in this article are ones we grapple with ourselves. We do not have the answers, but offer our thinking as part of an ongoing conversation. We have discovered first-hand the lack of a common understanding of key concepts, and differences arising from deeply held personal views and private experiences about ourselves and how we see the world. The heuristic is a pragmatic rather than theoretical tool that we use and find helpful. In our experience, the heuristic highlights different aspects of

1 The term 'Pākehä' is contested. For the purpose of this article we use it to refer to New Zealanders of European descent, however people self-identify. Issues of identity are discussed more fully in an earlier article by the authors (Torrie, Roorda, Peace, Dalgety \& Bailey, 2015). 
cultural competence and suggests a systematic process for exploring cultural competence, considering appropriate action, and enabling more fruitful conversations not just between Pākehā evaluators, but also perhaps in the future with Māori and Pasifika colleagues.

The article does not claim an ideological position about how Pākehā should or might be involved in evaluations involving Māori and other cultural groups different from our own, or recommend the best way of approaching these. It does, however, suggest that a reflexive orientation toward evaluative processes may be helpful in the context of developing cultural competence.

\section{Evaluator reflexivity}

We begin by locating this discussion in a wider context that links evaluation quality to evaluator credibility and competence. In respect to credibility, Patton (2002) has long maintained that in qualitative evaluation the "evaluator is the instrument" (p. 51), and that "the concepts and conceptual frameworks we use, whether unconsciously as a matter of tradition and training or intentionally as a matter of choice, carry embedded messages about what or who is important" (Patton, 2002, p.130). This process of reflecting on oneself, and the use of strategies to question our motivation, assumptions and worldviews is known as reflexivity (Bolton, 2010). Patton (2011) elaborates specifically on the way "reflexivity has entered the evaluation lexicon as a way of emphasizing the importance of self-awareness, political/ cultural consciousness, and ownership of one's own perspective" (p. 55). In Patton's sense, reflexivity encourages us to consider "what do I know, how do I know what I know, what shapes and has shaped my perspective, with what voice do I share my perspective and what do I do with what I have found?" (Patton, 2011, p. 55). This is relatively new thinking for evaluation but has a longer history in education and other, not dissimilar practice fields. For evaluators 
working from specific theoretical frames, such as feminist or critical theory perspectives, processes of self-reflection and transparency of orientation are more fundamental. (See, for example, Lather, 1991.) Thomas (2009, p. 63) describes reflexivity, incorporating "personal reflexivity" (how our personal experiences, values, and beliefs shape our practice) and "epistemological reflexivity" (how our assumptions about knowledge and the world impact on our practice), as the cornerstone of critical methodology.

There is, as yet, no systematic review of reflective practice in evaluation, but it appears that the importance of reflexivity, particularly in relation to developing cultural competence, is more readily accepted now than in the past (SenGupta et al., 2004). Indeed, reflective practice has been increasingly mainstreamed, so that Patton (2015) now argues that any report should include some information about the evaluator, as the instrument of a qualitative inquiry (including making any biases explicit as relevant), and also the reflexivity and reflectivity processes undertaken as part of the analysis process ( $\mathrm{p}$. 700). Patton further notes that "for better or worse, the trustworthiness of the data is tied directly to the trustworthiness of those who collect and analyse the data-and their demonstrated competence" (2015, p. 706). We suggest that, in working in the cultural space, tools to enhance and encourage evaluator reflexivity may be crucial for developing cultural competence, and such tools may help hone a critical edge for evaluators as instruments in credible and competent practice.

\section{What is cultural competence?}

Discussion about the subject of cultural competence is taking place globally (American Evaluation Association, 2011) and within other professions as well as evaluation (Bhui, Warfa, Edonya, McKenzie, \& Bhugra, 2007; DeSouza, 2008; Papadopoulos \& Lees, 2002). 
Despite an international literature, cultural competence is an evolving concept and it is difficult to find a succinct and agreed definition. Cultural competence begins with the recognition of the differences of views, values, beliefs, and experiences of different cultures, and "is rooted in how evaluators attend to issues of diversity, cultural responsiveness and multicultural validity" (Thompson-Robinson, Hopson \& SenGupta, 2004, p. 1). In 2009, Hopson was framing culturally responsive evaluation as "a theoretical, conceptual and inherently political position that includes the centrality of and attunedness to culture in the theory and practice of evaluation" (p. 431). In 2011, the American Evaluation Association adopted a statement on cultural competence that states: "Cultural competence is a stance taken toward culture, not a discrete status or simple mastery of particular knowledge and skills" (American Evaluation Association, 2011, n.p.). The competencies for local evaluators (ANZEA, 2011) and draft quality standards (ANZEA \& Families Commission, 2014) place culture at the centre of evaluation practice.

For the purpose of this article we use the term cultural competence to describe the importance and centrality of attending to culture in evaluation practice in a way that acknowledges and honours different perspectives and ways of being, in order to undertake ethical and effective evaluation (see Torrie et al., 2015, pp. 142-143 for a discussion of the term cultural competence and other current cultural evaluation terminologies). Cultural competence cannot be reduced to a mechanistic capability to carry out a task (such as riding a bike or using the appropriate Māori greetings); rather it is a reflective process involving conscious responsiveness by a practitioner to a particular context and location, at a point in time. Dunaway, Morrow, and Porter (2012) suggest that the most common paradigm of cultural competence has three components: cultural awareness, cultural knowledge, and cultural competence. 
Cultural awareness includes the process of understanding one's own culture, biases, tendency to stereotype, reference-group membership, and power relations. Cultural knowledge includes learning about the attitudes, values, beliefs, and behaviors of cultural groups. Cultural skills focus on communication ability and training learners to be aware of cross-cutting cultural issues. (Dunaway et al., 2012, p. 498)

\section{Aotearoa New Zealand context}

As we have proposed in an earlier paper (Torrie et al., 2015), evaluators in Aotearoa New Zealand by definition work in a cultural space as all policies and programmes-be they economic, environmental or social—have a cultural dimension (see also Hopson, 2009, p.431). Moewaka Barnes (2003) put it more directly: "All evaluation in this country, even if it does not appear to have direct relevance to Māori, raises obligations to be considered under the Treaty of Waitangi" (p. 146).

Moewaka Barnes' view derives from the partnership relationship vested under the Treaty of Waitangi in 1840, between tangata whenua (Māori, people of the land) and tangata tiriti (people of the treaty, the British Crown, government agencies, and settlers). This partnership notwithstanding, a robust body of evidence continues to be assembled as part of the Treaty settlement process since 1975 (Waitangi Tribunal, 2014), that describes the impact of colonisation for Māori that has resulted in a "dominant/subordinate pattern of intercultural relations" (Bishop \& Glynn, 1999, p. 12). Integral to this pattern have been the ways in which research and evaluation has historically been "done to" indigenous peoples by the dominant, white settler culture (Cram, 1997, p. 2; Smith, 1999) and the negative consequences of this research attention for Māori, Pasifika (settlers from the Pacific Islands), and other minority peoples. As a result, research and researchers in many Māori and other indigenous 
communities were/are viewed negatively or warily (Cram, 1997; Smith, 1999; Kawakami, Aton, Cram, Lai \& Porima, 2008).

Mention the word 'research' in a Māori setting and there will be accounts (usually second- or third-hand) of insensitive, unethical or even damaging behaviour by some previous researcher. For this reason, evaluators_-even Māori evaluators_are 'walking on poisoned ground' thanks to the activities of our predecessors. (Sporle, 2003, p. 66)

Kaupapa Māori approaches to research and evaluation have been emerging and developing over at least the last 30 years, alongside the re-emergence of Māori as an increasing presence in social, political, and economic institutions. Such approaches demand engagement and participation with Māori ways of being and knowing in the design, implementation, analysis and reporting of evaluations alongside other evaluation competencies. These evaluative processes are where Māori evaluators increasingly apply Māori evaluation practices and frameworks and assert the self-determining principle of by, with and for Māori or as Māori (Wehipeihana, 2011) with the reasonable expectation that previous Māori research and evaluation experiences of being done to will not be repeated. Pasifika and other minorities have been on their own path of questioning and challenging the status quo.

Pākehā evaluators also have a journey arising out of the particular social, historical, and constitutional context of this country. As Māori have asserted their right to tino rangatiratanga, and to different evaluation experiences, so too Pākehā have been provoked or encouraged to review our own role in evaluation and research.

\section{Challenges for Pākehā evaluators}

What are the particular challenges that Pākehā evaluators face in developing cultural competence? We know, from our own 
observations and experiences, and from the reporting of others, what some of these challenges look like. Cram (1997) describes the "bewildered Pākehā researcher who wants to engage in research with and for Māori but is uncertain what this means, let alone where to begin" (p. 1). Tolich (2002) coined the phrase "Pākehā paralysis" to describe Pākehā nervousness and tentativeness about participating in research and evaluation with Māori. Words such as confusing, complex, fraught, and fear of getting it wrong still inhabit conversations with some Pākehā colleagues about working cross-culturally.

There have been positive developments in capability over the past decade as a number of Pākehā evaluators now regularly work in the cross-cultural space and have trusted relationships with Māori colleagues. New ways in which Māori and Pākehā are working together in partnership are being written up and presented in research and evaluation literature (see, for example, Carpenter \& McMurchyPilkington, 2008; Cram \& Phillips, 2012; Jones \& Jenkins, 2008; Roorda \& Peace, 2009), and in these approaches there is a conscious attempt to recognise that different cultures hold different ontological and epistemological beliefs, and to address the question "what counts as proof for this culture?” (Davidson \& Lunt, 2003, p. 140). These developments notwithstanding, we would argue that building cultural competence and engaging appropriately with Māori in evaluation remains a troubled arena for many Pākehā evaluators.

Listed below are six issues and ten questions that represent some of the challenges that we, as Pākehā involved in evaluation, engage with in the quest for cultural competence:

\section{Participation and roles for Pākehā evaluators}

1. What evaluations should Pākehā practitioners be involved in and what role(s) should we play (Torrie, 2009)? 


\section{Significance of cultural competence in evaluation practice}

2. What weighting should we give cultural competence vis-à-vis other evaluation competencies?

3. To what extent does our cultural competence impact on the quality and robustness of an evaluation?

\section{Developing cultural competence}

4. How do we go about systematically developing cultural competence?

5. How do we know who to go to for guidance in a specific context?

\section{Evaluation practice}

6. How do we respond to colleagues and stakeholders, including commissioners, with differing perspectives about the importance and inclusion of cultural factors in an evaluation?

7. How do we build cultural competence into every stage of an evaluation including, for example, the analytical frame in data analysis?

8. How do we work in a way that is "culturally safe" (Ramsden, 1993) for us as Pākehā and for others?

\section{Working with specific groups}

9. What cultural competence do we require to work with particular groups who are different from ourselves?

\section{Safe and robust dialogue}

10. What environments exist and/or how can we create environments where we can have safe, robust discussions about cultural competence?

Why is it that issues of culture for many Pākehā are complex, difficult to articulate, contested, and sensitive (Torrie et al., 2015)? We offer five, related ideas for consideration here, which we think makes this an understandable, if not inevitable, reality. 
The first reason, that informs the others, is history. The Crown violations identified in the Treaty of Waitangi settlement process since 1975 means that many Pākehā are aware that an earlier learned history of this land-benign settlement stories, where "Maori and Pakeha work side by side" (Reed, 1961, p. 63) and race relations stories, in which New Zealand has the "the best race relations in the world" (de Bres, 2012)—no longer holds, but are still in a process of developing an understanding of this "new, less comfortable worldview" (Huygens, 2011, p.74). This process involves reviewing, unlearning and relearning, and, as with any process of change, this can be uncomfortable and destabilising. An integral part of the change process is resistance, which can be underpinned by many different things including excess uncertainty, concerns about competence, and loss of control (Moss Kanter, 2012).

The second reason is identity. For Pākehā, the implications of this revisiting of history challenges learned assumptions and beliefs about identity, culture and tradition, and "internalised self-attributions of decency and fairness" (Huygens, 2011, pp 75, 76). What does this new knowledge mean for the way we understand ourselves and our place in the world today? This question applies equally to Māori but their journey is a contrasting one, of "recovering [...] a tradition and a culture [...] rescuing those aspects of identity which served yesterday, and will serve today" (Huygens, 2011, pp 75, 76.)

The third reason is (lack of) knowledge. As part of the dominant culture in Aotearoa New Zealand many Pākehā are not "fluent" in either the language or the culture of our Treaty partner or other groups. When such fluency is lacking, working in any cultural space other than our own is to be ill-equipped to design and implement evaluations, or to analyse and interpret information that we gather. At a fundamental level this challenges our professional competence as evaluators and the validity and quality of our evaluation findings 
(Kirkhart, 1995, 2013). Furthermore, acquiring the necessary knowledge is not straightforward (where, for example, it is embedded in oral cultures, it is a relational rather than a transactional process, or is particular to individual iwi).

A fourth reason is (lack of) relationships. Many Pākehā have had limited or superficial experiences of Māori, Pasifika and other minority communities, living to some degree in siloed communities, even when physically co-existing. In our evaluation practice this can mean an absence of already established and trusted relationships to provide mentoring and guidance to undertake evaluations that are valid and credible when negotiating unfamiliar cultural terrain (Kirkhart, 2013, 1995; Wehipeihana, Davidson, McKegg, \& Sankar, 2010). This limited exposure to "other" can also result in a limited understanding of underlying discrimination and grievances experienced intimately by these communities, which means that crosscultural communication is complex and challenging. Some Pākehā evaluators have benefited from recent experiences of working with, and receiving support from, Māori and Pasifika colleagues, which has helped address some of these gaps.

The fifth reason is emotionality. Cultural competence has a clear emotional dimension. Developing cultural competence involves much more than improving our evaluation methodology toolkit. The process includes reflecting on our personal and ethnic identity and our location within the Aotearoa New Zealand society. There is a level of personal discomfort and intimacy as we engage with sensitive and unsettled ways in which we see ourselves and the world that is often uncommon in professional work contexts. Some of the emotional responses experienced by the authors in exploring cultural competence have included uncertainty, anxiety, dislocation, anger, and shame, along with a strong uplift of energy and mood, and a sense of freedom (Torrie et al., 2015, pp. 141, 142). 
Given these complexities, what kind of constructs and processes do Pākehā evaluators engage with, in exploring perplexing questions relating to culture, in order to determine how best to proceed? Although the ANZEA competencies and draft standards provide guidelines for practice, we could not find a framework for "working through" the confusion and uncertainty integral to this challenging and dynamic context. Hard-to-answer questions similar to those ten identified earlier were the catalyst for the authors (four evaluation practitioners and one academic) meeting together. In the process of grappling with these issues we constructed a framework as an aid to enquiry and practice. The heuristic that follows offers this framework for navigating these questions (Torrie et al., 2015).

\section{The heuristic}

The heuristic was developed following a lunchtime conversation at the ANZEA national conference in 2012 and a challenge made to Pākehā evaluators about the need for bilingual fluency. The Pākehā evaluators present at lunch, all committed to culturally competent practice, engaged in familiar process of "talking past each other" (Metge \& Kinloch, 1978). We seemed not to be able to "hear" and engage with what each other was saying, entered the conversation in different ways, and focused on different aspects of what was important and why. In short, the dialogue that occurred was fractured and did not aid communication or improve understanding.

In an attempt to understand this phenomenon, we, the authors, sketched out, or 'mapped' the different ways we saw Pākehā evaluators entering the discussion, supplemented by other aspects we also considered important. We discussed amongst ourselves that ideas relating to power are particularly challenging: they are influenced by the extent to which people see power imbricated in ordinary life, or as being more central than ideas of relationality, or as so paralysing 
(Tolich, 2002) we do not even try to "get it right"; and that all these views influence whether people will even enter a conversation about working cross-culturally.

There appeared to be two main ways in which Pākehā evaluators engaged with the conversation about working appropriately in the cultural space: first, reflecting on ourselves and our evaluator role in relation to Māori and other communities, and secondly, focusing on the other and the knowledge, skills, and relationships needed to become culturally competent evaluators. The heuristic we developed-affectionately known as the "octopus" 2 - is organised according to these two ideas and is framed using Symonette's "inside-out, outside-in" paradigm for cultural competence (2004, p. 99).

Symonette's (2004) inside-out framing refers to the process of reflection on "self-as-instrument and self-in-context" (p. 99). We think of this as the "internal" positioning of the evaluator: how we conceptualise and locate ourselves in relation to cultural competence. This is about ourselves as we are, in the moment we begin to address the question "what is needed for me to make sense of this situation?" We start with our embodied stories of identity, sense of place, and personal motivations. This requires reflection on our ways of knowing ourselves and seeing and understanding the world, on our motivations, and on the "embedded messages about what or who is important" (Patton, 2002, p. 130) in the conceptual frameworks we use; and the way all of this might shape our practice in relation to whether and how we should engage with Māori. While some of these ways of knowing may be constant, some may change when applied to specific evaluation contexts or over time.

Symonette's (2004) outside-in framing refers to the knowledge,

2 The heuristic developed in its current form organically, and its shape suggested its affectionate name. While completely separate from Te Wheke (the octopus model) developed by Rangimarie Rose Pere (1984), which is used more metaphorically in respect to Māori wellbeing, the heuristic shares the idea of a whole comprising linked and intertwining parts. 
skills, and processes required to engage with others. Symonette describes this as "expanding and enriching one's diversity-relevant knowledge and skills repertoire and one's professional evaluator's toolkit" (p. 99). Making a distinction between where we are at the moment, we pause to reflectively engage with what else we might need to enhance that engagement. The arms of the heuristic on this side highlight some of the knowledge, language, skills and relationships that may be required in traversing unfamiliar territory.

As noted earlier, the heuristic was developed as an aid to communication and sense-making. It is offered here to provide a shared language for raising issues of culture in evaluation and a process for facilitating discussion and finding options and solutions for addressing concerns or difficulties in working appropriately and consciously as Pākehā evaluators. It represents our thinking at a point and time, and is a work in progress. 
Figure 1. The heuristic

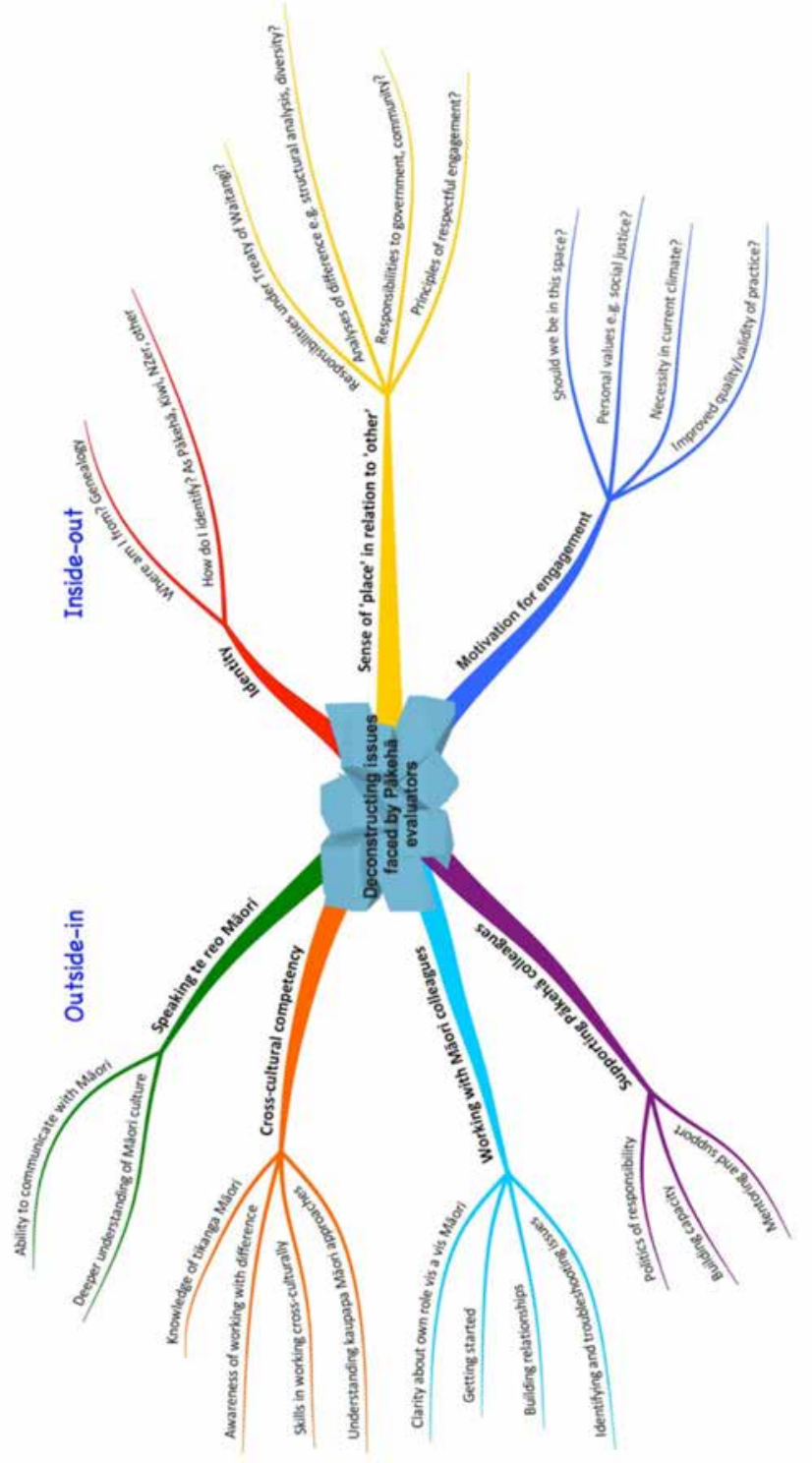




\section{Applying the heuristic to the challenges}

The heuristic incorporates different aspects of cultural competence. For any particular cultural competence challenge, different aspects of the heuristic will be more relevant than others. Locating the relevant arms for any given issue can be helpful in interrogating the issue, enhancing understanding, and exploring possible courses of action. We recommend using the heuristic in this flexible and responsive way, dependent on the issue at hand, rather than attempting to apply the whole of the heuristic to all challenges.

In Table 1 we have taken the ten common cultural competence challenges identified earlier and matched them to the relevant arms of the heuristic. The arms that match most directly with particular questions are highlighted in bold, and less-dominant linkages are in regular font. For example, question 10 about how to create an environment where robust dialogue and reflection can safely take place, maps against four arms of the heuristic. It maps strongly against the two arms of supporting Pākehà colleagues and working with Màori/'other' colleagues, and to a lesser degree with identity and motivation for engagement. The sub-branches offer a more focused investigation of the subject. For example, the sub-branches supporting Pākehà colleagues asks: "What are politics of responsibility? How do we build capacity with colleagues? What role would mentoring play in this context?"

Table 1. Cultural competence challenge questions

\begin{tabular}{|c|c|}
\hline \multicolumn{2}{|c|}{$\begin{array}{l}\text { Cultural competence challenge questions for Pākehā evaluators } \\
\text { mapped against the seven arms of the heuristic }\end{array}$} \\
\hline Challenge questions & Arms (and sub-branches) of the heuristic \\
\hline $\begin{array}{l}\text { Participation and roles for Päkehā } \\
\text { evaluators } \\
\text { 1. What evaluations should we } \\
\text { be involved in and what role(s) } \\
\text { should we play? }\end{array}$ & $\begin{array}{l}\text { - Sense of 'place' in relation to 'other' } \\
\text { - Working with Māori/'other' colleagues } \\
\text { - Motivation for engagement } \\
\text { - Cross-cultural competency }\end{array}$ \\
\hline
\end{tabular}




\begin{tabular}{|c|c|}
\hline $\begin{array}{l}\text { Significance of cultural competence in } \\
\text { evaluation practice } \\
\text { 2. What weighting should we give to } \\
\text { cultural competence vis-à-vis other } \\
\text { evaluation competencies? }\end{array}$ & $\begin{array}{l}\text { - Cross-cultural competency } \\
\text { - Sense of 'place' in relation to 'other' } \\
\text { - Motivation for engagement } \\
\text { - Working with Mãori/'other' colleagues }\end{array}$ \\
\hline $\begin{array}{l}\text { 3. To what extent does our cultural } \\
\text { competence impact on the quality } \\
\text { and robustness of an evaluation? }\end{array}$ & $\begin{array}{l}\text { - Cross-cultural competency } \\
\text { - Sense of 'place' in relation to 'other' } \\
\text { - Motivation for engagement }\end{array}$ \\
\hline $\begin{array}{l}\text { Developing cultural competence } \\
\text { 4. How do we go about developing } \\
\text { cultural competence? }\end{array}$ & $\begin{array}{l}\text { - Identity } \\
\text { - Cross-cultural competency } \\
\text { - Sense of 'place' in relation to 'other' } \\
\text { - Working with Māori/'other' colleagues } \\
\text { - All other arms of the octopus }\end{array}$ \\
\hline $\begin{array}{l}\text { 5. How do we know who to go to for } \\
\text { guidance in a specific context? }\end{array}$ & $\begin{array}{l}\text { - Sense of 'place' in relation to others } \\
\text { - Cross-cultural competency } \\
\text { - Working with Māori/'other' colleagues } \\
\text { - Identity }\end{array}$ \\
\hline $\begin{array}{l}\text { Evaluation practice } \\
6 . \text { How do we respond to } \\
\text { colleagues and stakeholders, } \\
\text { including commissioners, with } \\
\text { differing perspectives about } \\
\text { the importance and inclusion of } \\
\text { cultural factors in an evaluation? }\end{array}$ & $\begin{array}{l}\text { - Sense of 'place' in relation to 'other' } \\
\text { - Motivation for engagement } \\
\text { - Identity } \\
\text { - Supporting Pākehā colleagues } \\
\text { - Working with Māori/'Other' colleagues }\end{array}$ \\
\hline $\begin{array}{l}\text { 7. How do we build cultural } \\
\text { competence into every stage of } \\
\text { an evaluation, e.g., the analytical } \\
\text { frame in data analysis? }\end{array}$ & $\begin{array}{l}\text { - Cross-cultural competency } \\
\text { - Working with Māori/'other' colleagues } \\
\text { - Sense of 'place' in relation to 'other' } \\
\text { - Motivation for engagement }\end{array}$ \\
\hline $\begin{array}{l}\text { 8. How do we work in a way that is } \\
\text { 'culturally safe' for us as Pākehā and } \\
\text { for others? }\end{array}$ & $\begin{array}{l}\text { - Identity } \\
\text { - Sense of 'place' in relation to other } \\
\text { - Motivation for engagement } \\
\text { - Cross-cultural competency }\end{array}$ \\
\hline $\begin{array}{l}\text { Working with specific groups } \\
\text { 9. What cultural competence do we } \\
\text { require to work with particular } \\
\text { groups who are different from } \\
\text { ourselves? }\end{array}$ & $\begin{array}{l}\text { - Cross-cultural competency } \\
\text { - Sense of 'place' in relation to 'other' } \\
\text { - Speak te reo/language of 'other' } \\
\text { - Working with Māori/'other' colleagues }\end{array}$ \\
\hline $\begin{array}{l}\text { Safe and robust dialogue } \\
\text { 10. What environments exist and/or } \\
\text { how can we create environments } \\
\text { where we can have safe, robust } \\
\text { discussions about cultural } \\
\text { competence? }\end{array}$ & $\begin{array}{l}\text { - Supporting Pākehā colleagues } \\
\text { - Working with Māori/'other' colleagues } \\
\text { - Identity } \\
\text { - Motivation for engagement. }\end{array}$ \\
\hline
\end{tabular}




\section{Case examples}

Three scenarios are provided below where the heuristic is used as a framework to systematically guide reflection and dialogue on the specific cultural competence issues being raised. The case examples explore Questions 1, 6, and 9 in Table 1.

\section{Case example A-Participation and roles for Pākehā evaluators} Question 1: What evaluations should we be involved in and what role(s) should we play?

A typical scenario is an evaluation of a government programme that has a focus on Māori. The evaluation is needed to inform a pending decision about whether to roll out the programme nationwide. The government agency approaches Pākehā evaluators it has previously worked with, who have a good knowledge of the policy area and are available to undertake the evaluation in a tight timeframe. The evaluators ask themselves: "Should we accept the contract, and if so, what roles and actions do we need to consider given we will be working with Māori community providers and programme participants"?

In such a scenario, the elements of the heuristic potentially most helpful in exploring this question are: (i) sense of 'place' in relation to 'other'; (ii) motivation for engagement; (iii) cross-cultural competency; and (iv) working with Mãori colleagues. The sub-branches include questions such as: What responsibilities under the Treaty of Waitangi are applicable in this scenario? Who is best positioned to undertake such work? Should we as Pākehā be in this space? What is our knowledge of tikanga Māori and skills working cross-culturally? What is the necessity in the current climate? How will these decisions impact on the quality and validity of the evaluation? And if there is a decision by Pākehā to accept a contract: Have we built relationships with Māori colleagues? What are the principles for respectful engagement? How clear are we about our own role vis-à-vis Māori colleagues? How 
do we identify and troubleshoot issues with Māori colleagues?

In a real-life example of the scenario described above (Roorda $\&$ Peace, 2009), we can also retrospectively apply the heuristic to review and explore what occurred. In this example, the evaluators accepted the contract. At the time they addressed questions such as whether they could draw on the support of Māori colleagues, and whether their knowledge of tikanga Māori skills in working cross culturally with respectful engagement were sufficient for the task. Recognising their limitations, they actively sought Māori expertise from within and outside the agency to provide oversight, and assist with fieldwork and analysis.

Despite these strategies, several significant difficulties were encountered. One of these was a lack of consultation with all relevant community stakeholders. The evaluators visited staff from the Māori provider organisations selected by the agency, but no consultation was held with other providers. When the findings were presented at a national meeting attended by all providers, some criticised the evaluation design because it focused on a small number of providers and ignored the experiences of others (Roorda \& Peace, 2009).

Another difficulty encountered was the evaluators' lack of knowledge about the cultural expertise required on the project. The evaluators worked with the agency to identify a Māori staff member who could assist with fieldwork and analysis. However, as the evaluation progressed, it became apparent that this person did not have the required skills which the evaluators failed to recognise. In contrast, a second fieldwork team member was identified by a Māori evaluation colleague, and engagement with stakeholders and quality of data capture was materially better in this case (Roorda \& Peace, 2009).

This case example highlights some interesting points. First, some issues that arose were structural and beyond the evaluation team's control, meaning that commissioning agencies need to work 
alongside evaluators in attending to cultural competence. Secondly, cultural competence issues arise throughout the evaluation process and need to be attended to appropriately at each stage. Thirdly, there is a need for a systematic approach to different cultural competence questions that arise in the course of an evaluation. In this case, a systematic application of the heuristic would also have addressed the following questions (see Table 1): Question 3-To what extent does our cultural competence impact on the quality and robustness of the evaluation; Question 7-How do we build cultural competence into every stage of an evaluation; and Question 9-What cultural competence do we need to work with particular groups who are different from ourselves? Finally, the heuristic may have engaged the evaluators in a more in-depth exploration of whether, as Pākehā, they should be in this space, and their ability to assess their own cross-cultural expertise and the assistance they needed.

\section{Case example B-Evaluation practice}

Question 6: How do we respond to colleagues and stakeholders, including commissioners, with differing perspectives about the importance and inclusion of cultural factors in an evaluation?

In working as a team to develop the heuristic and record our journey, holding differing views about culture and cultural competence became familiar and sometimes uncomfortable professional challenges for us. These views reflect our diverse personalities, backgrounds, values, world-views, training, and influences, and adjustments to a revised history of this land. This particular scenario describes the writing of this article.

Even though the authors share a common goal of working appropriately and effectively with Māori and others different from ourselves, we differ in how we frame, understand and engage with this process, and therefore our strategies for achieving that goal. Our 
process for addressing these differences was to each better understand and articulate our own beliefs and positionality. Then we were better able to identify similarities and unpack points of difference, and come to agreement about how to proceed.

We came to think of ourselves as each having a number of continuums on which we locate ourselves at different places at different times. For example, some of the writers find the concepts of structural analysis and decolonisation frameworks an important starting point for understanding and analysing New Zealand history and society (Consedine \& Consedine, 2005; Huygens, 2011; Smith, 1999), and suggesting possible approaches for developing cultural competence. In this view there are shared experiences that occur, including relative access to power, because of one's membership of a particular group. These writers believe in engaging with a comprehensive package of concepts and constructs, within which the application of and engagement with decolonisation frameworks and structural analysis are essential components.

A second continuum is the approach to making sense of history and society as described in recent anthropological and historical literature (King, 2003, 1999; Salmond, 2014; Waitangi Tribunal, 2014). Another of the writers is exploring this as a preferred starting point for any discussion about culture and cultural competence. In this analysis, recent New Zealand history and society is viewed as a meeting and clashing of differing world systems (Salmond, 2008). While Pākehā power, values, structures and world views continue to be seen as the dominant force, Salmond (2012) contends that the analysis of society and relations between the Pākehā and Māori world systems cannot be reduced to simple abstract binaries, such as coloniser and colonised.

There is more agreement among the writers of the centrality of relationships and relationality to developing cultural competence. 
This writing project required strong professional and personal relationships between the writers to enable respectful and honest dialogue while working through our different perspectives. This dialogue required collective effort, time, careful listening and reflection, and a level of trust and courage to explore our differences. We have found that similar qualities need to be developed in our relationships with other evaluation stakeholders including those different from ourselves (Māori, Pasifika and other minority groups), commissioners, and policy makers.

We began with and returned to the heuristic in the process of developing this article, as a place to clarify our points of view when we became aware we were, yet again, talking past each other. We reflected mostly on five of the heuristic arms to assist us in unpacking our differences: Sense of "place" in relation to "other"; motivation for engagement; identity; supporting Pākehā colleagues; and working with Màori/"other" colleagues. As with the first case, beginning with sense of place in relation to "other", we discussed our views about responsibilities under the Treaty of Waitangi, how to make sense of or analyse our society, including our settlement history, and how we view Pākehā in our society. Underlying these views we found our deeper perspectives were related to the identity arm: how do we identify as individuals, where do we come from and how do these influences inform our values and worldview, and what are our personal values and beliefs? In relation to the supporting Päkehà colleagues arm, questions included: how do we build each other's capacity, and how do we mentor each other?

\section{Case example $\mathrm{C}$-Working with specific groups}

Question 9: What cultural competence do we require to work with particular groups who are different from ourselves?

This a hypothetical scenario where the heuristic is used in the 
design phase to systematically identify some key elements required for culturally competent practice. In this case a government agency requests a summative evaluation of a cultural development programme for New Zealand Chinese communities which includes the objective of raising awareness of these communities in wider New Zealand society.

The arms of the heuristic that we would expect to be applied are: Sense of "place" in relation to "other", cross-cultural competency, speak te reo Mãorillanguage of "other", and working with "other" colleagues. The focus of the sense-of-place enquiry would include: what is the settlement history of this group, what are or have been the responsibilities of government to this group, and what are the key principles for respectfully engaging with them? Questions under the cross-cultural competency arm might ask: what skills do we have working cross culturally, what knowledge do we have of Chinese culture, what evaluation approaches would be most appropriate for this group, what ability do we have to communicate in the language of the target group? And, finally, questions relating to working with colleagues would ask us to consider: what is our role with Chinese colleagues, how would we build relationships with them, how might we troubleshoot issues with them?

Cultural competence would involve the evaluators having an awareness of the long Chinese settlement history in Aotearoa, the significant economic and social contribution of Chinese to specific regions and the nation as whole, the institutional and social discrimination they experienced from a [Pākehā] government and the formal apology made to them, ${ }^{3}$ and developing a knowledge of Chinese culture, protocols, language, and their position in New Zealand society. This preliminary list of factors has been developed without guidance

3 The Chinese were the only nationality that paid a poll tax to enter this country for work and they were unable to become New Zealand citizens until 1951 (New Zealand Government, 2002). 
from Chinese colleagues; having such relationships would be essential to inform the design of the evaluation, including stakeholder engagement, evaluation team membership, team roles, data collection, and analysis.

\section{Discussion}

We think that use of the heuristic can assist the cultural competence of Pākehā practitioners. As noted in the previous case examples, it is a flexible tool that can be used prospectively in the design of evaluations, for example in discussions with commissioners and stakeholders, or retrospectively to reflect on what occurred and how cultural concerns might have been better taken into account.

Our own early practice of applying the heuristic has assisted us in three interrelated ways: First, by providing a common framework and language for dialogue; secondly, by enhancing our consciousness about our own approach to culture and cultural competence; and thirdly, by enhancing our understanding of what informs the perspectives of "the other". These are discussed further below.

1. A common framework and language for our dialogue about culture and cultural competence.

Culture and cultural competency, as already noted, is a complex, contested, sensitive, and increasingly important dimension of evaluation practice in Aotearoa New Zealand. The heuristic offers us a visual conceptual picture of the space, some of its key elements, and relationships between these elements. It provides guidance where reflection is required, or choices need to be made, to promote cultural competence. The heuristic also provides a potential language and vocabulary to support clearer and richer dialogue for Pākehā practitioners about culture and cultural competency. The heuristic explicitly acknowledges that individuals enter the dialogue at different points, bringing their own perspectives, identities, stories, 
and world views. This framing promotes a pluralistic dialogue that respects difference and enables participants to safely enter the discussion from wherever they are. It can provide a tool for engaging with others where addressing such questions is complex, and sensitive and/ or "un-discussable" (Dick \& Dalmau, 1992).

2. Enhanced consciousness of what informs our approach to culture, cultural competence and evaluation.

The heuristic has the potential to raise the consciousness of the practitioner to the various influences on our culture, cultural competence, and evaluation. By systematically reflecting on our identity, individual history, and relationships with the other, awareness is heightened about how these affect evaluation decisions about who and what is important.

3. Enhanced consciousness of what informs the world of the "other" and their perspective of culture, cultural competence, evaluation and the world of the "other".

The arms of the heuristic offers a way of reaching out to, exploring, engaging with, and comprehending stakeholders, who are other. The outside/in arm of the heuristic clarifies the knowledge and skills the practitioner requires about the tikanga/culture, kawa/protocols and reo/language to effectively engage and understand the other, particularly Māori in Aotearoa New Zealand. The heuristic also helps the practitioner make sense of the other by locating the other historically, in New Zealand society, and in relation to the Pākehā practitioner. Additionally, it assists us to understand the views and decisions of fellow Pākehā practitioners, commissioners or others with a stake in the evaluation process.

Our early experiences of applying the heuristic have also given rise to two important insights about its use. The first insight is the importance of having a trusted group to work with to share this journey towards cultural competence. As already discussed, this can be a 
sensitive and challenging area for many Pākehā evaluators, including ourselves. We have experienced a clear emotional dimension present in some of our conversations, partly derived from having to acknowledge our own not knowing, our perceived lack of competence, and our fumbling, uncertain attempts when articulating potentially new ways forward. We have come to see the capacity to be personally vulnerable with one another as an essential element to engage substantively in the discourse. This kind of dialogue required us to have consciousness of, and care for, ourselves and others, honed listening skills, and openness to multiple ways of seeing. Interpersonal trust was indispensable. Creating a trusted group that is ongoing enables us to continue to engage rather than back off from conversations that are troublesome to us.

The second insight is the value of developing our own library of cultural competence resources. Some approaches to understanding, developing, and applying cultural competence in our practice have resonated more strongly with us than others. For example, we have perhaps been more drawn to decolonisation frameworks, or cultural responsiveness approaches, or critical race theory. We are each building a personal library of cultural competence resources (for example, "how to" guidelines; key journal articles from Aotearoa New Zealand and internationally on cultural competence, critical race theory, cultural responsiveness, decolonisation, kaupapa Māori approaches, indigenous methodologies, white privilege; learnings from discussions with colleagues; newspaper articles about the Treaty settlement process and so on) that may fit within or challenge our personal framework for understanding cultural competence, but engage us in this important reflexive process.

One approach that has had significant impact for us is to identify, gather and use powerful questions in our evaluation practice. The heuristic presents a number of these questions, as discussed in the 
case examples earlier. Additionally, some of the writers have found the following question to be both succinct and powerful when exploring the appropriateness of participating in an evaluation: "Who am I to do this [specific] evaluation?"4 The question obviously raises issues of evaluator competency, including cultural competence skills and knowledge in this particular context. However, the question also goes beyond these familiar parameters and asks more challengingly, "Who am I [the practitioner] in relation to this specific evaluation and evaluand?"

\section{Next steps}

Culture and cultural competence is growing in its significance in professional evaluation practice. Culturally competent Pākehā evaluators are required to produce evaluations that are valid, credible, and equitable. This is a complex and challenging space to negotiate. In this article we have named some of the key challenges that Pākehā evaluators may face, and we have used the heuristic to investigate these challenges.

We have described the heuristic, highlighted its flexibility for use, and identified its benefits. Firstly, it provides a common framework and language to support the often-complex and challenging dialogue about culture and cultural competence. Secondly, the heuristic opens up ideas for deeper reflection on what informs our approach to culture, cultural competence, and evaluation. Finally, the heuristic encourages greater consciousness about what informs the perspective and approach to culture, cultural competence, evaluation, and the world of the other. Furthermore, it is a framework that is, itself, open to adaptation, reinterpretation, and representation in alternative forms for different and emerging contexts.

4 Kataraina Pipi posed this question to Moana-o-Hinerangi in a session at the 2010 South Island ANZEA Symposium. 
Where to next? Some of our ideas include reviewing and reworking the heuristic to make it more useful as a diagnostic and developmental tool, developing practical steps, or questions, or both, for each branch. A key process is taking this tool back to a range of Pākehā evaluator colleagues to see how well it reflects their viewpoint and meets their needs. Their experiences can be gathered via workshops, conferences, or a blog. We need also to listen to the views of, and engage in discussion with, our New Zealand colleagues who are Māori, Pasifika, or from other minority groups. Then there is the need to hear the cultural competence challenges of evaluation colleagues who are descended from European settlers in, say, Australia, Canada and the United States.

We have opted for a dialogic strategy of enhancing cultural competence and assumed, at least to some extent, that relevant competencies for Pākehā evaluators can be developed if some initial self-awareness is present and opportunities for motivated dialogue exist. However, there is a bigger challenge that we would invite the evaluation education community to participate in: how might this desirable development be taught to incoming and existing cohorts of evaluation practitioners?

There is no endpoint to the cultural competence journey. We are finding there are a number of paths toward competence, some more linear and some more of a spiraling process. These paths themselves move within the broader, evolving space that is evaluation practice in Aotearoa New Zealand in 2015. Our Māori colleagues continue to encourage and support us. This journey is challenging, unsettling, and important. 


\section{Glossary}

Aotearoa New Zealand

iwi extended kinship group, tribe, nation, people, nationality, race kawa customs

kaupapa topic, policy, matter for discussion, plan

kaupapa Māori a framework and way of working built on a Māori world view

Pākehā New Zealanders of European descent

Pasifika Indigenous peoples of the Pacific Islands who have settled in Aotearoa New Zealand

te reo Māori the Māori language

tikanga custom

tikanga Māori Māori custom

tino rangatiratanga self-government, sovereignty

tangata whenua indigenous people of the land

tangata tiriti people of the treaty, or New Zealanders of non-Māori origin, originally the British Crown and now government agencies Waitangi Place where "The Treaty of Waitangi/Te Tiriti of Waitangi" was signed, New Zealand's founding document, meant to be a partnership between Māori and the British Crown.

te wheke the octopus

\section{References}

American Evaluation Association. (2011). Public statement on cultural competence in evaluation. Fairhaven, MA: Author. Retrieved from http://www.eval.org/p/cm/ld/fid=92

Aotearoa New Zealand Evaluation Association. (2011). Evaluator competencies. Retrieved from http://www.anzea.org.nz/wpcontent/ uploads/2013/05/110801_anzea_evaluator_competencies_final.pdf Aotearoa New Zealand Evaluation Association \& Families Commission. (2014). Proposed evaluation standards for Aotearoa New Zealand 
Exposure draft. Retrieved from http://www.anzea.org.nz/wp-content/ uploads/2014/08/FMC562-Evaluation-Standards-A.pdf

Bailey, R. (2010). A précis of the evaluation competency literature: a working document Wellington, Aotearoa New Zealand Evaluation Association. Retrieved from: http://www.anzea.org.nz/evaluation/ evaluation-competencies-project/

Bhui, K., Warfa, N., Edonya, P., McKenzie, K., \& Bhugra, D. (2007).

Cultural competence in mental health care: a review of model evaluations. BMC Health Services Research 7(1): 15.

http://dx.doi.org/10.1186/1472-6963-7-15

Bishop, R., \& Glynn, T. (1999). Culture counts: Changing power relations in education. Palmerston North: Dunmore Press.

Bolton. G., E. (2010). Reflective practice: Writing and professional development (3rd ed.). London: Sage Publications.

Carpenter, V. M., \& McMurchy-Pilkington, C. (2008). Cross-cultural researching: Māori and Pākehā in Te Whakapakari. Qualitative Research, 8(2), 179-196. http://dx.doi.org/10.1177/1468794107087480

Consedine, R. (2014). Anti-racism and Treaty of Waitangi activism. Retrieved from: http://www.TeAra.govt.nz/en/ anti-racism-and-treaty-of-waitangi-activism

Consedine, R., \& Consedine, J. (2005). Healing Our history: The challenge of the Treaty of Waitangi (2nd ed.). Auckland: Penguin.

Cram, F. (1997). Developing partnerships in research: Pākehā researchers and Māori research. Sites, 35, 44-63.

Cram, F., \& Phillips, H. (2012). Claiming interstitial space for multicultural, transdisciplinary research through community-up values. International Journal of Critical Indigenous Studies, 5(2), 36-49.

de Bres, J. (2012). Race relations law marks 40th anniversary. Retrieved 14 February 2015 from http://www.hrc.co.nz/2012/04/01/ race-relations-law-marks-40th-anniversary/

DeSouza, R. (2008). Wellness for all: The possibilities of cultural safety and 
cultural competence in New Zealand. Journal of Research in Nursing, 13(2), 125-135. http://dx.doi.org/10.1177/1744987108088637

Davidson, C., \& Lunt, N. (2003). Introduction to Section Four. In N. Lunt, C. Davidson \& K. McKegg (Eds.), Evaluating Policy and Practice: A New Zealand Reader. Wellington: Pearson.

Dunaway, K., Morrow, J., \& Porter, B. (2012). Development and validation of the cultural competence of program evaluators (CCPE) self-report scale. American Journal of Evaluation, 33(4), 496-514. http://dx.doi.org/10.1177/1098214012445280

Dick, B., \& Dalmau, T. (1992 , July) Discussing the undiscussable: improving group effectiveness and openness. Proceedings from the Second World Congress on Action Learning. Brisbane: University of Queensland.

Hopson, R., K. (2009). Reclaiming knowledge at the margins: Culturally responsive evaluation in the current evaluation moment. In K. Ryan and J. B. Cousins (Eds), The SAGE international handbook of educational evaluation, Thousand Oaks, CA: Sage Publications.

Huygens, I. (2011). Developing a decolonisation practice for settler colonisers: A case study from Aotearoa New Zealand. Settler Colonial Studies, 1(2), 53-81. http://dx.doi.org/10.1080/2201473X.2011.10648812

Jakob-Hoff, M., \& Coggan, C. (2003). Core competencies for evaluators. In N. Lunt, C. Davidson \& K. McKegg (Eds), Evaluating policy and practice: A New Zealand reader (pp. 132-137). Auckland: Pearson Education.

Jones, A., \& Jenkins, K. (2008). Rethinking collaboration-Working the indigene-coloniser hyphen. In N. K. Denzin, Y. Lincoln \& L. T. Smith (Eds.), Handbook of critical and indigenous methodologies. Thousand Oaks, CA: Sage Publications.

Kawakami, A. J., Aton, K., Cram, F., Lai, M. K., \& Porima, L. (2008). Improving the practice of evaluation through indigenous values and methods: Decolonising evaluation practice-returning the gaze from Hawai'i and Aotearoa. In N. L. Smith \& P. R. Brandon (Eds.), Fundamental issues in evaluation. New York: The Guilford Press. 
King, M. (1999). Being Pakeha now. Auckland: Penguin.

King, M. (2003). Penguin history of New Zealand. Auckland: Penguin.

Kirkhart, K. E. (2013, April). Repositioning validity. Paper presented at the Inaugural Culturally Responsive Evaluation and Assessment (CREA) Conference, Chicago, IL.

Kirkhart, K. (1995). 1994 conference theme: Evaluation and social justice seeking multicultural validity: A postcard from the road. American Journal of Evaluation, 16(1), 1-12. http://dx.doi.org/10.1177/109821409501600101

LaFrance, J. (2004), Culturally competent evaluation in Indian Country. New Directions for Evaluation, 102, 39-50. http://dx.doi.org/10.1002/ev.114

Lather, P. (1991). Getting smart: Feminist research and pedagogy withlin the postmodern. New York: Routledge.

Lynch, E., \& Hanson, M. (Eds). (1992). Developing cross-cultural competence: A guide for working with young children and their families. Baltimore, MD: Paul H. Brookes Publishing.

Metge, J., \& Kinloch, P. (1978). Talking past each other: Problems of crosscultural communication. Wellington: Victoria University Press.

Moewaka Barnes, H. (2003). Maori and evaluation: Some issues to consider. In C. Davidson. N. Lunt, \& K. McKegg (eds.), Evaluating policy and practice: A New Zealand reader: Wellington: Pearson Education.

Moss Kanter, R. (2012). Ten reasons people resist change. Harvard Business Review. Retrieved from https://hbr.org/2012/09/ten-reasons-people-resistchang.html

New Zealand Government. (2002). Address to Chinese New Year celebrations: Prime Minister [Media release]. Retrieved from http://www.beehive.govt.nz/speech/address-chinese-new-year-celebrations

Papadopoulos, I. \& Lees, S. (2002). Developing culturally competent researchers. Journal of Advanced Nursing 37(3), 258-264. http://dx.doi.org/10.1046/j.1365-2648.2002.02092.x

Patton, M. Q. (2002). Qualitative research \& evaluation methods (3rd ed.). Thousand Oaks, CA: Sage Publications. 
Patton, M. Q. (2011). Essentials of utilization-focused evaluation. Thousand Oaks, CA: Sage Publications.

Patton, M. Q. (2015). Qualitative research and evaluation methods (4th ed.). Thousand Oaks CA: Sage Publications.

Ramsden, I. (1993). Cultural safety in nursing education in Aotearoa (New Zealand). Nursing Praxis in New Zealand. 8(3), 4-10.

Reed, A. W., \& Collins, A. G. (1961). A boys' and girls' history of New Zealand. Wellington: A.W. Reed.

Roorda, M., \& Peace, R. (2009). Challenges to implementing good practice guidelines for evaluation with Māori a Pākehā perspective. Social Policy Journal of New Zealand, 34, pp. 73-89.

Salmond, A. (2008). Two worlds: Tangled histories. Paper presented at The Waitangi Rua Rautau Lecture Series. Retrieved from http://www.firstfound.org/two_worlds_anne_salmond_wrrt_08.htm

Salmond, A. (2012). Beyond the binary_shifting New Zealand's mindset. Paper presented at the First Sir Paul Reeves Memorial Lecture. Retrieved from http://www.radionz.co.nz/assets/cms_uploads/000/000/019/ Beyond_the_Binary_-_Shifting_New_Zealands_mindset_\%28text\%29.pdf

Salmond, A. (2014). 2014 Rutherford Lectures: Experiments across Worlds. Wellington. Retrieved from http://www.royalsociety.org.nz/events/annual/ rutherford-lecture/2014-rutherford-lectures-experiments-across-worlds/

SenGupta S., Hopson, R., \& Thompson-Robinson, M. (2004). Cultural competence in evaluation: An overview. New Directions for Evaluation, 102, 95-109. http://dx.doi.org/10.1002/ev.112

Smith, L. T. (1999). Decolonising methodologies: Research and indigenous peoples. Dunedin: University of Otago Press.

Sporle, A. (2003). “So Maori development fits in how?”-The realities of attempting to implement kaupapa Maori practice evaluation in a contractual situation. In N. Lunt, C. Davidson \& K. McKegg (Eds.), Evaluating policy and practice: A New Zealand Reader. Wellington: Pearson Education. 
Stevahn, L., King, J. A., Ghere, G., \& Minnema, J. (2005). Establishing essential competencies for program evaluators. American Journal of Evaluation, 26, 43-59. http://dx.doi.org/10.1177/1098214004273180

Symonette, H. (2004). Walking pathways toward becoming a culturally competent evaluator: Boundaries, borderlands, and border crossings. New Directions for Evaluation, 102, 95-109. http://dx.doi.org/10.1002/ev.118

Thomas, V. G. (2009). Critical race theory: Ethics and dimensions of diversity in research. In D. Mertens \& P. Ginsberg (Eds.), Handbook of social research ethics. Thousand Oaks CA: Sage Publications. http://dx.doi.org/10.4135/9781483348971.n4

Thompson-Robinson, M., Hopson, R., \& SenGupta, S. (2004). Editors' notes. New Directions for Evaluation, 102, 95-109. http://dx.doi.org/10.1002/ev.111

Tolich, M. (2002). Pākehā "paralysis": Cultural safety for those researching the general population of Aotearoa. Social Policy Journal of New Zealand, 19, 164-178.

Torrie, R. (2009). Whether or not to go there: Päkehā evaluators and evaluations involving Mãori. Wellington: Unpublished paper.

Torrie, R., Roorda, M., Peace, R., Dalgety, M., \& Bailey, R. (2015). Peeling open the kiwi: Reterritorialising [white] evaluation in Aotearoa New Zealand. In S. Hood, K. Hopson, \& H. Frierson (Eds.), Continuing the journey to reposition culture and cultural context in evaluation theory and practice. Charlotte, NC: Evaluation and Society Information Age.

Veracini, L. (2011) Introducing. Settler Colonial Studies, 1(1), 1-12. http://dx.doi.org/10.1080/2201473X.2011.10648799

Waitangi Tribunal. (2014). Report on stage 1 of the Te Paparahi o Te Raki inquiry released [Press release]. Retrieved from http://www.justice.govt.nz/tribunals/waitangi-tribunal/news/ report-on-stage-1-of-the-te-paparahi-o-te-raki-inquiry-released 
Wehipeihana, N., Davidson, E. J., McKegg, K., \& Shanker, V. (2010). What does it take to do evaluation in communities and cultural contexts other than our own. Journal of Multidisciplinary Evaluation, 6(13), 182-192.

Wehipeihana, N. (2011). Keynote presentation: Creating space for indigenous values, practices and leadership in evaluation-The Aotearoa New Zealand experience. Paper presented at the 3rd Biennial South African Monitoring \& Evaluation Association Conference, Johannesburg, SA.

\section{The authors}

Rae Torrie, Evaluation Works

Email: rae.torrie@xtra.co.nz

Robin Peace, Massey University

Robyn Bailey, Evaluation Works

Mathea Roorda, Evalueresearch

Mark Dalgety, Mark Dalgety Consulting 